\title{
Enhanced Surface Wettability of Rice Straw with Alkaline Pretreatment
}

\author{
Bing Liu ${ }^{1}$, Fenghu Wang ${ }^{*}, 1$, Xiaodong Zhu ${ }^{*}, 1$ and Anying $\mathrm{Jiao}^{2}$ \\ ${ }^{I}$ College of Material Science and Engineering, Northeast Forestry University, Harbin 150040, China \\ ${ }^{2}$ Forestry School, Northeast Forestry University, Harbin 150040, China
}

\begin{abstract}
To improve the surface wetting properties of rice straw, effects of distilled water and four alkali pretreatment on the straw surface wettability were analyzed. The straw surface contact angle at different time points was measured by JC2000A contact angle measuring apparatus, optical microscope (OM) and scanning electron microscopy (SEM) combined with a linear regression technique for parameter extraction. The results show that the surface wettability of rice straw obtained significant improvement after alkali treatment and the contact angle decreases until it reaches equilibrium (force balance, heat balance and chemical equilibrium) over time. The contact angle has the maximum rate of change at the mass fraction of $1 \%$ in $10 \mathrm{~min}$ by $\mathrm{NaNH}_{2}$ pretreatment of the rice straw with the contact angle decrease gradient of $20.64 \%$. The contact angle has the smallest decrease gradient of $3.6 \%$ by $\mathrm{CaH}_{2}$ pretreatment of the rice straw under the same conditions, however, a large number of $\mathrm{CaCO}_{3}$ formation lead to the contact angle which does not change significantly over time. When smooth wax inside and outside the straw surface is removed, there has been similar to the "etched" phenomenon with wettability improved obviously by SEM image analysis. The optimum conditions of processing technology were obtained through orthogonal test: concentration of $\mathrm{NaOH}$ is $0.6 \%$, solvent ratio $1: 3.5$ and reaction time $12 \mathrm{~h}$.
\end{abstract}

Keywords: Dynamic wettability, rice straw, alkali pretreatment, dynamic contact angle, wetting model, wetting model, $\mathrm{NaOH}$ treatment, regression analysis, orthogonal test.

\section{INTRODUCTION}

Dynamic wetting is characterized by some of the liquid (water, adhesives, paint, oxidizing agent, cross-linking agent, waterproofing agents, dye and various modification solution, etc.) in contact with the solid surface, wetting, spreading and easing of penetration and effectiveness on the surface [1]. This property is very important to the interface bonding, surface finishing and various modified treatment process [2, 3].

Adhesive joint, simply said, it is to make the adhesive bonding and adhesive bonding to form the bulk of the necessary mechanical strength of a stable system [4]. If you simply consider the adhesive joint process, which including variety of processes the adhesive liquefaction, flow, diffusion, osmosis, solidification, deformation and destruction. Each process has a certain effect to the strength of the bonding and to the understanding that the adhesive joint only on a particular process is not possible [5-7]. The adhesive must be infiltrated and spread on the solid (rice straw) surface, which is the necessary condition to obtain high-strength adhesive joints [8,9]. This paper focuses on the wettability and to consider issues from the perspectives of thermodynamics and kinetics of adhesive joint.

Wettability refers to the process that the air above the solid (rice straw) surface is gradually replaced by liquid (adhesive) [10]. The degree of wetting from liquid to solid is usually represented by contact angle (contact angle) $\theta$ or $\cos \theta$.

\footnotetext{
*Address correspondence to these authors at the College of Material Science and Engineering, Northeast Forestry University, Harbin 150040, China; Tel: +86-451-82190819; Fax: +86-451-82190819;

E-mails: ice8515@163.com,pse4646@126.com
}

When the droplet of adhesive is in contact with the straw surface, the balance condition is shown in Fig. (1). The angle $\theta$, through the surface tangent line of the junction point of solid, liquid and gas phase and the attached surface of the liquid, which is called the contact angle. When three phases equilibrium [11], the Eq. 1 set up.

$\gamma_{S G}=\gamma_{L G} \cdot \cos \theta+\gamma_{S L}$

$\gamma S G$-Solid - gas interfacial tension;

$\gamma L G$-Liquid - gas interface tension;

$\gamma S L$-Solid - liquid interfacial tension;

$\gamma S L$-Solid - liquid interfacial tension.

$\gamma L G$

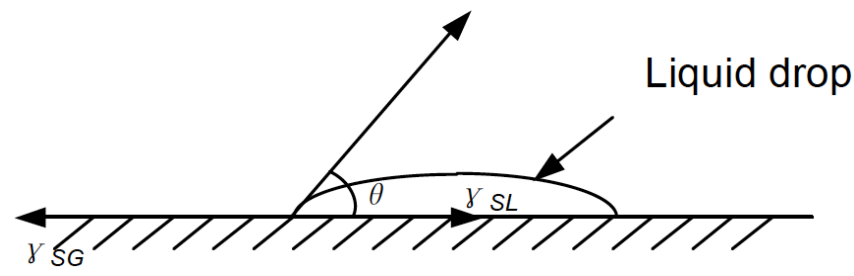

Fig. (1). Liquid wetting on solid surface.

$\theta=0^{\circ}, \cos \theta=1$, completely wet that liquid to the solid surface, such as the capillary rise in the concave hemispherical surface;

$\theta<90^{\circ}, 0<\cos \theta<1$, the solid can be wetted by liquid, such as dropping the adhesive on wood;

$\theta>90^{\circ}, \cos \theta<0$, the solid is not wetted by the liquid, such as dropping the mercury on the glass; 
$\theta=180^{\circ}, \cos \theta=-1$, completely non - wetting.

Eq. 1 can be obtained from the adhesion $(W a)$, wetting (Wi) and the spreading coefficient $(S)$ with $\cos \theta$ and $\gamma L G$ of expression and value these parameters according to the experimental determination of $\cos \theta$ and $\gamma L G$.

The above-mentioned contact angle refers to the equilibrium contact angle $\theta e$, which is under certain temperature and pressure, from the moment the contact angle of droplets fell the solid surface (the initial contact angle $\theta i$ ), and after some time to go through to reach the equilibrium value $\theta e$ [12]. For different natures of the contact interface, it is not only depends on the thermodynamic conditions of wettability between them, that is the interface compatibility between the two parameters, surface energy, the actual surface of the liquid and solid adhesive bonding system, but also considers the dynamics of the interface between two molecules contacting processes and the actual rate of diffusion and osmosis. Roughness has been defined as Eq. 2:

$I=\frac{\cos \theta_{i}}{\cos \theta_{e}}$

For the study of wetting properties, many world-wide scholars study the characterization of the interface and try to improve the structure and properties of the interface then to explore the interface characteristics of the relationship between overall performance and the material carried out extensive and in-depth study [13-17] while most studies have been focused on wood materials [18-20].

Zisman, W.A. (1962) studied constitution effects on adhesion and adhesion [21], Gray pointed out that wood surface wettability decreased with increasing time, which means that free energy from the surface of the wood varies with surface aging changes [22]. Herczeg, A. (1965) studied wettability of wood [23] and Chen, C.M. (1970) studied the wettability of wood through determining the instantaneous or equilibrium contact angles at the solid / adhesive interface [24]. Hse, C.Y. (1972) confirmed the quality of the contact angle is proportional with the glue [25]. In 1977, the research of Nguyen and some others suggested that the free energy in the solid and liquid surface is very close to the critical surface tension $(\gamma C)$. Therefore, the solid surface free energy can be estimated through measuring the critical surface tension. Nguyen once measured extracting Douglas fir and pine wood wettability before and after changing, both obtained by the extraction of wood treatment reduced the contact angle $\theta$, which improved wettability, This study provides an important basis for the later studies on the wettability of wood extract [26]. Sheldon (2001) and Dunky (1998) studied dynamic adhesive wettability of Douglas fir (pseudosuga menziesii) and southerm pine and Gardner (2001) reported wood surface properties including wettability [27].

Our research team (Zhiming liu 2002) in the previous study analyzed Wheat Straw and Wheat Straw fibers, in Figs. (2-4) Wheat Straw carbohydrate rich outer surface and a certain amount of $\mathrm{SiO}_{2}$, carbohydrate material for the skeleton to form a doped $\mathrm{SiO}_{2}$ organic compounds and stratum corneum (closed layer), Urea-formaldehyde resin (UF) resin is difficult to immerse within the stratum corneum of Rice Straw, affecting the matrix resin wetting, diffusion and infiltration, making it difficult to produce a qualified board. Isocyanine adhesive (MDI) of new adhesives to create new conditions for the manufacture of Rice Straw particleboard, its production costs are high, which has a strong chemical reaction activity, particularly in reacting with water (even small amounts of water). This study confirmed that the wettability of wheat straw is especially important to improve the bonding mechanism and as well as to provide the theoretical basis for efficiently use of resources.

This study will use Rice Straw as a substrate using JC2000A Contact Angle Measuring Apparatus and optical microscope (OM) and scanning electron microscopy (SEM) to establish rice straw wetting model, which aims to improve the bonding properties of the rice straw surface and analyze the contact angle of the straw surface wettability with distilled water and Alkali $\left(\mathrm{NaOH}, \mathrm{NaNH}_{2}, \mathrm{CaH}_{2}, \mathrm{KOH}\right)$ treatment. Orthogonal test is to optimize their treatment options, as the particleboard hot-pressing process development and process of making a reasonable analysis of the details, then theoretically guide the manufacturing process of medium density straw board.

\section{MATERIALS AND METHODS}

\subsection{Materials Preparation}

Rice straw was obtained from outside Harbin City, Heilongjiang Province, China. The straw was removed leaf and sheath and dried in the sun and be cut into $3-5 \mathrm{~cm}$ length pieces. Sample surface texture, color and interception sites as far as possible, the optimal pretreatment conditions in their processing reserve.

Treatment agent: Distilled water, Northeast Forestry University lab self-making, temperature of $37.0 \pm 0.1^{\circ} \mathrm{C}$; modified urea-formaldehyde resin (UF), Northeast Forestry University, self- making, solid content of $64 \%$; Isocyanate adhesive (MDI), Northeast Forestry University self- making, solid content of $32 \%$; $\mathrm{NaOH}$ (AR), $\mathrm{NaNH}_{2}$ (AR), $\mathrm{CaH}_{2}$ (AR), KOH (AR), Fine Chemical Co., Ltd. Of Tianjin Central: $\mathrm{mg} / \mathrm{kg}>96 \%$.

Test apparatus: JC2000A Contact Angle Measuring Apparatus (CAA, made in shanghai, P.R. China). Optical microscope (OM): Olympus, BX51. Scanning electron microscopy (SEM): OLYMPUS, SZX12.

\subsection{Materials Preparation}

Wetting measurements were using the JC2000A Contact Angle Measuring Apparatus . Images of the droplet shape on the rice straw surface were captured by a camera and saved every 10 s. During the wetting measurements, as time elapsed, the drop shape tended to stabilize (equilibrium contact angle was obtained). The contact angles at both ends of the measured drop were averaged. Nine data points were taken for each recorded drop to obtain a curve of contact angle $v s$ time. Five replicates were averaged for each sample.

Sample size: $2 \times 15 \mathrm{~mm}$

Drop volume: $5 \mu 1$

Temperature of the lab: $15.0 \pm 2.0^{\circ} \mathrm{C}$ 


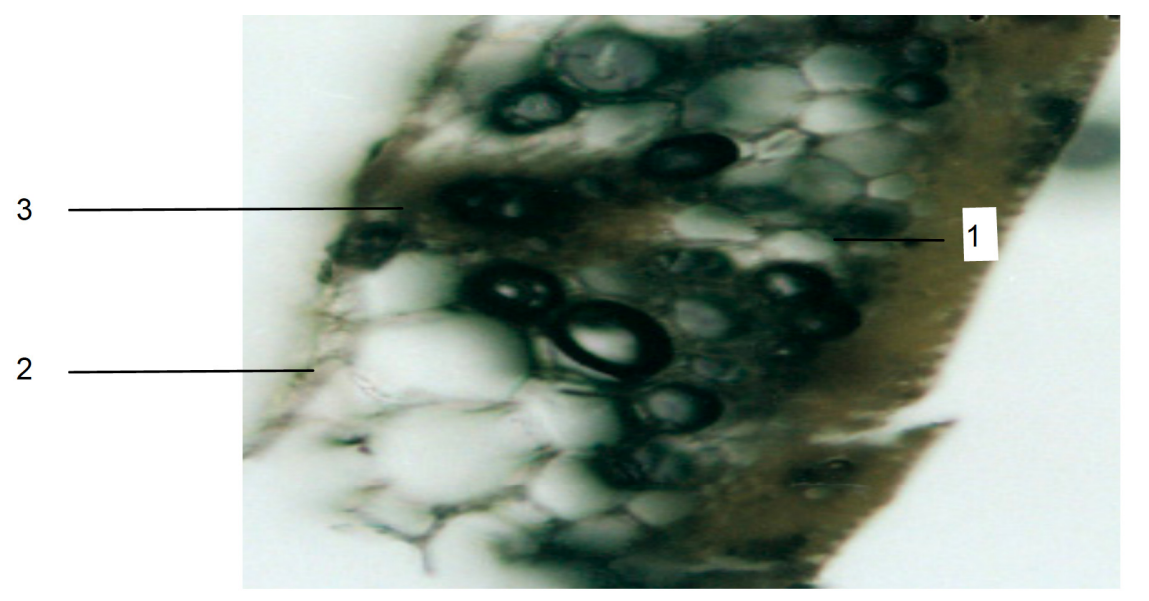

1. Epidermis tissue 2. Parenchyma tissue 3 . Vascular tissue

Fig. (2). Cross Section of wheat straw LM $\times 200(\mathrm{OM})$.

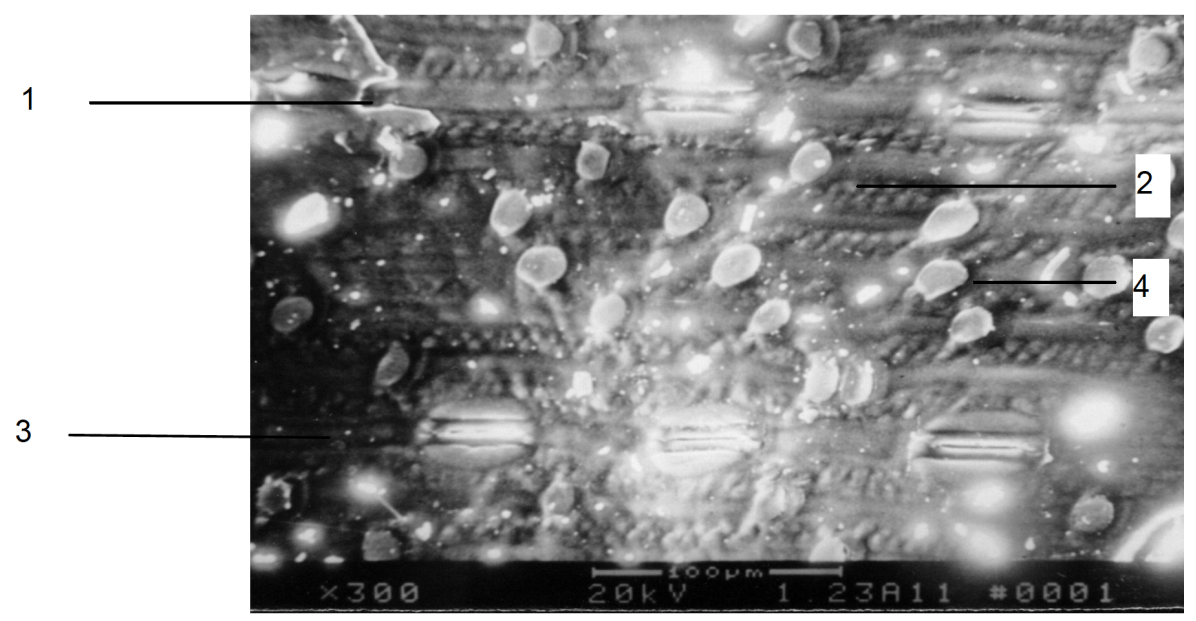

Fig. (3). Exterior surface of wheat straw.

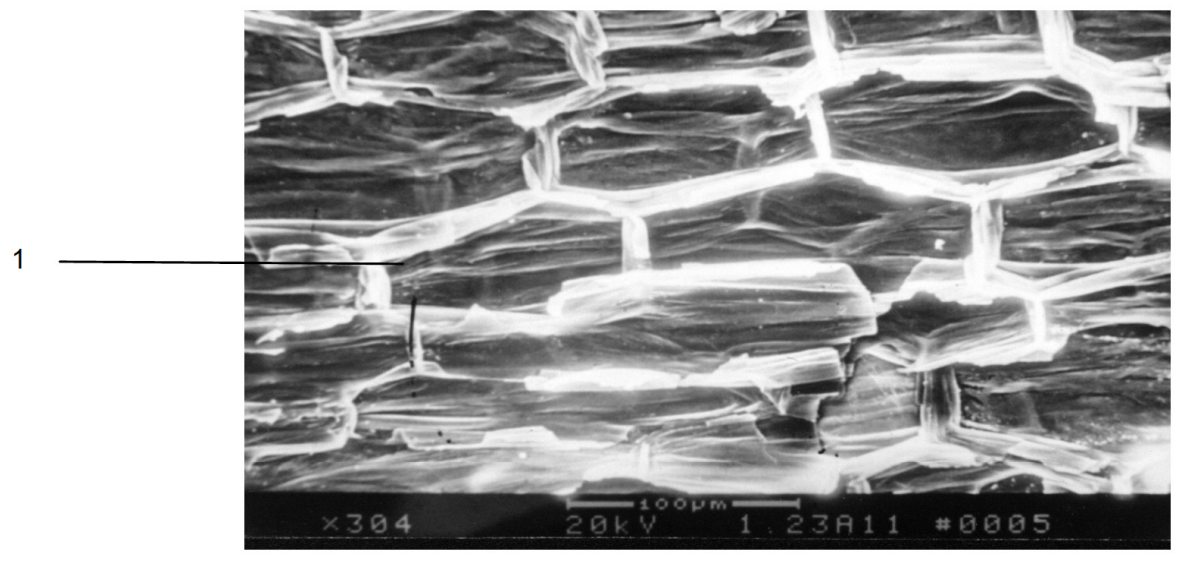

1. Parenchyma cell

Fig. (4). Interior surface of wheat straw.

Measuring time: 0s, 10s, 20s, 50s, 100s, 150s, 250s, $400 \mathrm{~s}, 600 \mathrm{~s}$ and $900 \mathrm{~s}$

\section{Reduplicate: 3 .}

(2) Rice straw surface were carried out with four kinds of alkali wetting spray, no lye outflow; Rice straw was dried after wetting for 8 hours, and the sample was measured with the water content of $3-4 \%$; Rice straw surface contact angle was measured under different treatment conditions, and effects of treatment on the wettability of rice straw was compared. Specification treatment conditions are shown in Table $\mathbf{1}$.

(3) In addition, Rice straws were saturated by spraying them with $1.6 \% \mathrm{NaOH}$. During the course of praying and wetting, almost no diluted alkali leached out from 
the treated rice straws. After $8 \mathrm{~h}$, the rice straws were dried to a moisture content of approximately $4 \%$ in an oven at $95^{\circ} \mathrm{C}$ to $102^{\circ} \mathrm{C}$ in order to be used for manufacturing particleboard. In the wettability experiment, the treated straws were stored in the air for 2 weeks after drying. Finally, the interior and exterior surfaces of the treated rice straws were observed with the OM and SEM. At the same time, we could observe the structural changes of rice straw surfaces.

Table 1. Factors and Levels of Orthogonal Experiment

\begin{tabular}{|c|c|c|c|c|}
\hline Factors Levels & $\begin{array}{c}\text { Treatment } \\
\text { Agent }\end{array}$ & \multicolumn{2}{|c|}{ Concentration/\% } & Time/Min \\
\hline \hline 1 & $\mathrm{NaNH}_{2}$ & 1 & 3 & 30 \\
\hline 2 & $\mathrm{NaOH}$ & 1 & 3 & 90 \\
\hline 3 & $\mathrm{KOH}$ & 1 & 3 & 60 \\
\hline 4 & $\mathrm{CaH}_{2}$ & 1 & 3 & 10 \\
\hline
\end{tabular}

(4) Established wetting model is used to describe contact angle changes as a function of time, the constant $(\mathrm{K}$ value )in the model is used to quantify the spreading and penetrating rate of the liquid/straw system. Orthogonal experimental design method, three main factors were selected test level 3, following Table 2, each experiment was repeated three times. Derived from the analysis of the optimal process conditions, process parameters were selected for review screening test.

Table 2. Factors and Levels of Orthogonal Experiment

\begin{tabular}{|c|c|c|c|}
\hline Factors Levels & $\begin{array}{c}\text { Concentration/\% } \\
\text { A }\end{array}$ & $\begin{array}{c}\text { Liquid Ratio } \\
\text { B }\end{array}$ & $\begin{array}{c}\text { Time/h } \\
\mathbf{C}\end{array}$ \\
\hline \hline 1 & 0.3 & $10 \mathrm{~g}: 45 \mathrm{ml}$ & 6 \\
\hline 2 & 1.5 & $10 \mathrm{~g}: 25 \mathrm{ml}$ & 12 \\
\hline 3 & 0.6 & $10 \mathrm{~g}: 35 \mathrm{ml}$ & 24 \\
\hline
\end{tabular}

According to the principle of orthogonal design table, the use of $\mathrm{L}_{9}\left(3^{4}\right)$ orthogonal table, and developed the following experimental scheme, shown Table 3.

\section{RESULTS AND DISCUSSION}

\section{(1) Analysis of Surface Contact Angle}

Learning from the predecessors' theory, model of wood and adhesive wetting, and basing on the surface of distilled water diffusion in the rice straw to quantitative evaluation of diffusivity - permeability coefficient $\mathrm{K}$ under different treatment conditions the surface wetting properties of rice straw.

When liquid droplets (spray) drop on the surface of the rice straw [28], there will be three processes occur successively: the first process is the formation of the initial contact angle between the droplets and a liquid-solid interface of rice straw. The second process happens after the formation of the contact angle, which is that, the droplet's diffusivity in the surface of rice straw. The third process is that in the meantime of the droplet diffusivity, droplets penetrating inside the rice straw. Shows in Fig. (5).

Table 3. Orthogonal Experiments Design of $\mathrm{L}_{9}\left(3^{4}\right)$

\begin{tabular}{|c|c|c|c|c|}
\hline Experiment No. & $\begin{array}{c}\mathbf{A} \\
\mathbf{1}\end{array}$ & $\begin{array}{c}\mathbf{B} \\
\mathbf{2}\end{array}$ & $\begin{array}{c}\mathbf{C} \\
\mathbf{3}\end{array}$ & $\mathbf{4}$ \\
\hline \hline 1 & $1(0.3)$ & $1(1: 4.5)$ & $1(8)$ & 1 \\
\hline 2 & $1(0.3)$ & $2(1: 2.5)$ & $2(12)$ & 2 \\
\hline 3 & $1(0.3)$ & $3(1: 3.5)$ & $3(24)$ & 3 \\
\hline 4 & $2(1.5)$ & $1(1: 4.5)$ & $2(12)$ & 3 \\
\hline 5 & $2(1.5)$ & $2(1: 2.5)$ & $3(24)$ & 1 \\
\hline 6 & $2(1.5)$ & $3(1: 3.5)$ & $1(8)$ & 2 \\
\hline 7 & $3(0.6)$ & $1(1: 4.5)$ & $3(24)$ & 2 \\
\hline 8 & $3(0.6)$ & $2(1: 2.5)$ & $1(8)$ & 3 \\
\hline 9 & $3(0.6)$ & $3(1: 3.5)$ & $2(12)$ & 1 \\
\hline
\end{tabular}

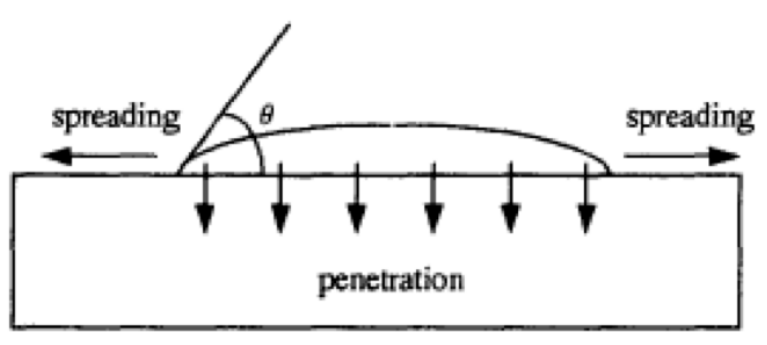

Fig. (5). Distilled water wetting the surface of the straw.

The first process-the formation of the contact angle, involving liquid-solid interface thermodynamics; The second process - diffusivity, due to the changes in surface energy of rice straw, due to adsorption and kinetic factors; the third process - permeability is relevant to surface structure of rice straw. Comparing with anisotropic porous material wood although the outer surface of straw has stoma, but owing to the keratin with poor permeability. However, the diffusivity and permeability on the surface the straw remain, which can be confirmed from the changes of the contact angle over time [29-31].

Fig. (6) shows the contact angle of the surface of the liquid in the straw, the trend over time $(0 \mathrm{~s}, 10 \mathrm{~s}, 20 \mathrm{~s}, 50 \mathrm{~s}$, $100 \mathrm{~s}, 150 \mathrm{~s}, 250 \mathrm{~s}, 400 \mathrm{~s}, 600 \mathrm{~s}$ and $900 \mathrm{~s}$ ), Fig. (7) shows using linear regression analysis on each test, the contact angle with time for processing, diffusivity-permeability coefficient $\mathrm{K}$. Fig. (8) shows experimental K value.

Experiments confirmed that during the liquid wetting process of the rice straw surface, the contact angle changes over time. When the droplet just drops on the straw surface, the contact angle is large and declined rapidly over time, then more and smaller, until the relative balanced. For an ideal liquid-solid system, the velocity of variation of diffusion and penetration over time can be expressed as the following Eq. 3:- $\frac{d \theta}{d t}=-K \theta$ 


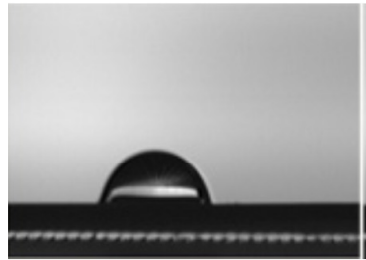

Os

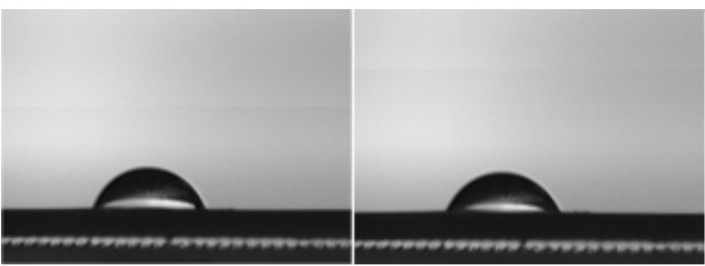

$150 \mathrm{~s}$

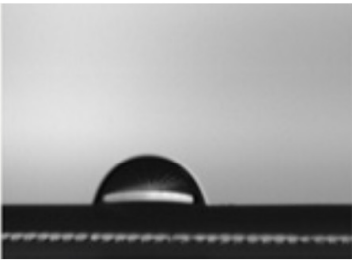

$10 \mathrm{~s}$

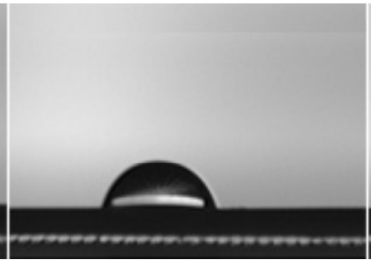

$20 s$

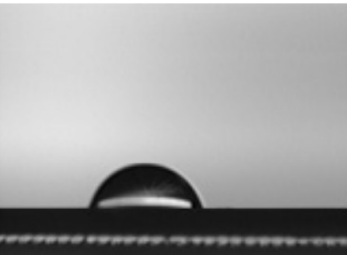

$50 \mathrm{~s}$

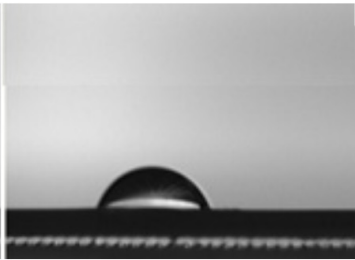

$100 \mathrm{~s}$

Fig. (6). Image of the contact angle of the surface of straw at different time interval.

$K^{-}$Constant of change of contact angle; $\theta$-Contact angle $\left(^{\circ}\right) ; t$-Time (s).

When the diffusivity and permeability ultimately tend to zero, Eq. 3 can add a constraint changed to Eq. 4:

$\frac{d \theta}{d t}=-K \theta\left(1-\frac{\theta i-\theta}{\theta i-\theta}\right)$

$\theta i$-Initial contact angle; $\theta e^{- \text {Balance contact angle }}$

Integration order by Eq. 4:

$\theta=\frac{\theta i \cdot \theta e}{\theta i+(\theta e-\theta i) \exp \left[K\left(\frac{\theta e}{\theta e-\theta i}\right) t\right]}$

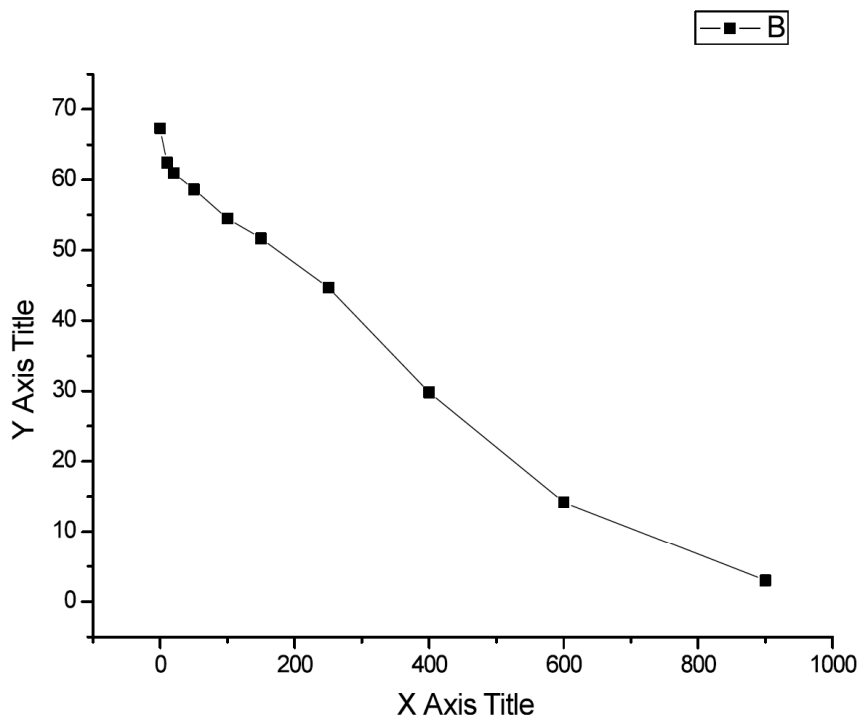

Fig. (7). Curve of the surface contact angle of rice straw

Seen from the above equation, rate of change of contact angle refers to the proliferation and infiltration rate of liquid on the surface of rice straw, thus the $\mathrm{K}$ in Eq. 5 may also be called as diffusivity-permeability constant. For the above equations showed the diffusion - permeability of the situation of liquid on the surface of the solid (rice straw). At this point, the physical meaning of $K$ is the measure of diffusion and permeability of the droplet in the surface of the rice straw. $K$ value is larger, indicating that the diffusion and penetration of the plastic drop are faster in the surface of straw, the sooner you can achieve balance and better advantageous on the formation of "mechanical anchor effect".

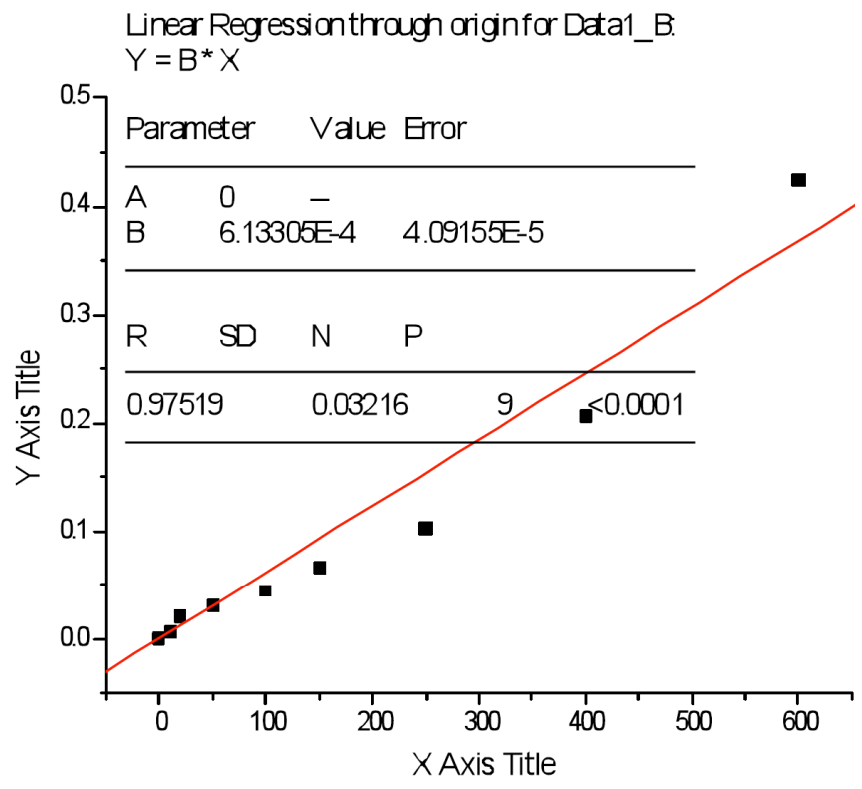

Fig. (8). Linear function of equation $Y=K t$.

When $K=0$, then $\theta i=\theta e$, it means that diffusion and permeation processes do not happen.

Regulate the Eq. 5 for Eq. 6:

$\frac{\theta e-\theta i}{\theta e} \cdot \ln \frac{\theta i(\theta e-\theta i)}{\theta(\theta e-\theta i)}=K t$

In season

$Y=\frac{\theta e-\theta i}{\theta e} \cdot \ln \frac{\theta i(\theta e-\theta)}{\theta(\theta e-\theta i)}$,

then the Eq. 6 into Eq. 7:

$Y=K t$ 
$\mathrm{Y}$ is a linear function which changes over time, diffusivity-permeability coefficient $K$ is the slope of the linear function, thus, we can get diffusion - permeability coefficient $K$ from the linear fit value.

Fig. (8) is an obtained $\mathrm{K}$ value using of origin data analysis software.

Through the calculation and analysis, we can see that $\theta$ gradually decreases over time until it reaches equilibrium (force balance, heat balance and chemical equilibrium), shown in Fig. (6). Droplet wetting process on the surface of rice straw can be accurately described by means of wetting model. Diffusivity-permeability coefficient $K$ can be used to evaluate the spread of liquid-solid system and permeability rate.

\section{(2) Influence of Alkali Treatment}

Fig. (9) shows the changes of contact angle of rice straw surface with different Alkali treatment.

The results show: rice straw alkali treatment can effectively improve the surface contact angle. After four kinds of alkali treatment, rice straw surface contact angle becomes less with lengthening of time; the impact of different alkali-type on the wettability of rice straw is significant, but the mass fraction of alkali docking has little effect on the rate of change antennae.

$\mathrm{NaOH}$ treatment effect changed significantly over time and it proved that $\mathrm{NaOH}$ can effectively improve the surface wetting properties of rice straw; $\mathrm{KOH}$ treatment effect changed little over time [32]; $\mathrm{NaNH}_{2}$ processing rice straw with the contact angle of the mass fraction of $1 \%$, the maximum change rate within $10 \mathrm{~min}$ and the gradient of contact angle decreased 20.64\%; Under the same condition, $\mathrm{CaH}_{2}$ processing rice straw reduces the contact angle of the gradient is the smallest, the value is $3.6 \%$. The reason may be the liquid itself, due to the nature of the liquid, $\mathrm{CaH}_{2}$ dissolved in water then produced $\mathrm{Ca}(\mathrm{OH})_{2}$, with the extension of time, the solution absorbed $\mathrm{CO}_{2}$ from the air, then produced $\mathrm{CaCO}_{3}$ and resulted in lye failure; $\mathrm{CaCO}_{3}$

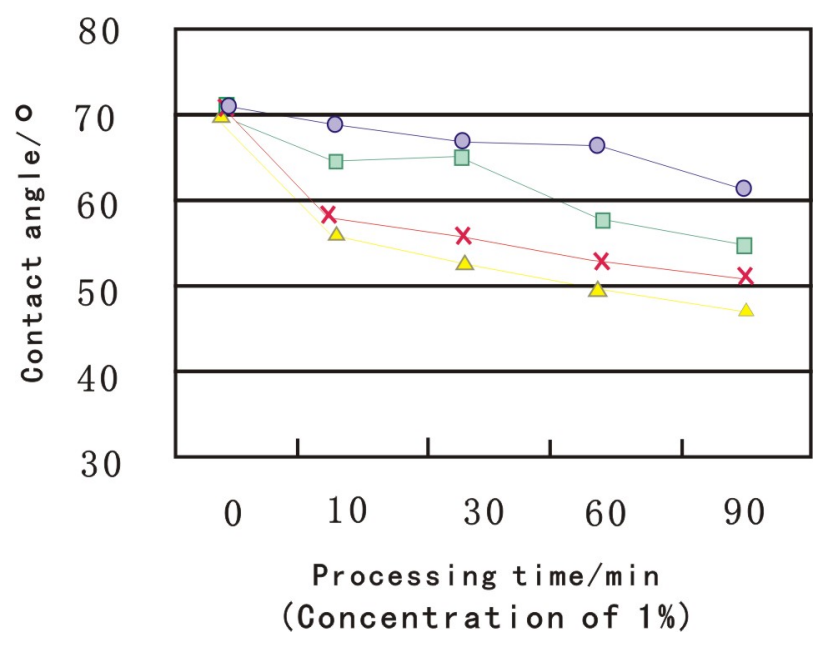

attached to the straw surface, made the contact angle change inconspicuously over time.

By calculation and analysis, we can see that over time, $\theta$ gradually decreases until it reaches equilibrium (force balance, heat balance and chemical equilibrium), shows in Fig. (6). Wetting process of rice straw droplet surface by means of wetting model can be accurately described. Diffusivity-permeability coefficient $K$ can be used to evaluate the spread of liquid-solid system, permeability rate.

\section{(3) SEM Analysis}

Fig. (10) shows internal and external surface SEM images of rice straw in the $1.6 \% \mathrm{NaOH}$ pretreatment before and after the control.

Fig. (10C, D) for $1.6 \% \mathrm{NaOH}$ treated of rice straw surface, for the outer surface of rice straw has the dense smooth wax things and the main chemical composition of it is a fatty alcohol and the formation of higher fatty acids esters, esters soluble in alkali, so the smooth wax things is removed, This creates favorable conditions for the rice straw wetting, diffusion and penetration [33]. Pictures can be seen from the $\mathrm{NaOH}$ treatment, the uneven surface of rice straw shows a phenomenon similar to the "etching", therefore, the surface wettability of rice straw can be improved by $\mathrm{NaOH}$ treatment.

\section{(4) Orthogonal Optimization of Process}

According to the established wetting model, the diffusivity-permeability coefficients $K$ of each rice straw treated by $\mathrm{NaOH}$ were determined.

Table 4 shows following Table $\mathbf{2}$, Orthogonal set obtained in the proliferation of each experiment - the value of diffusivity-permeability coefficient $K$.

Table 5 shows experimental results and analysis of variance.

From Table 5, we can see that with diluted $\mathrm{NaOH}$ treatment, the capacity of diffusivity permeability coefficient of rice straw has been notably enhanced. Concentration is
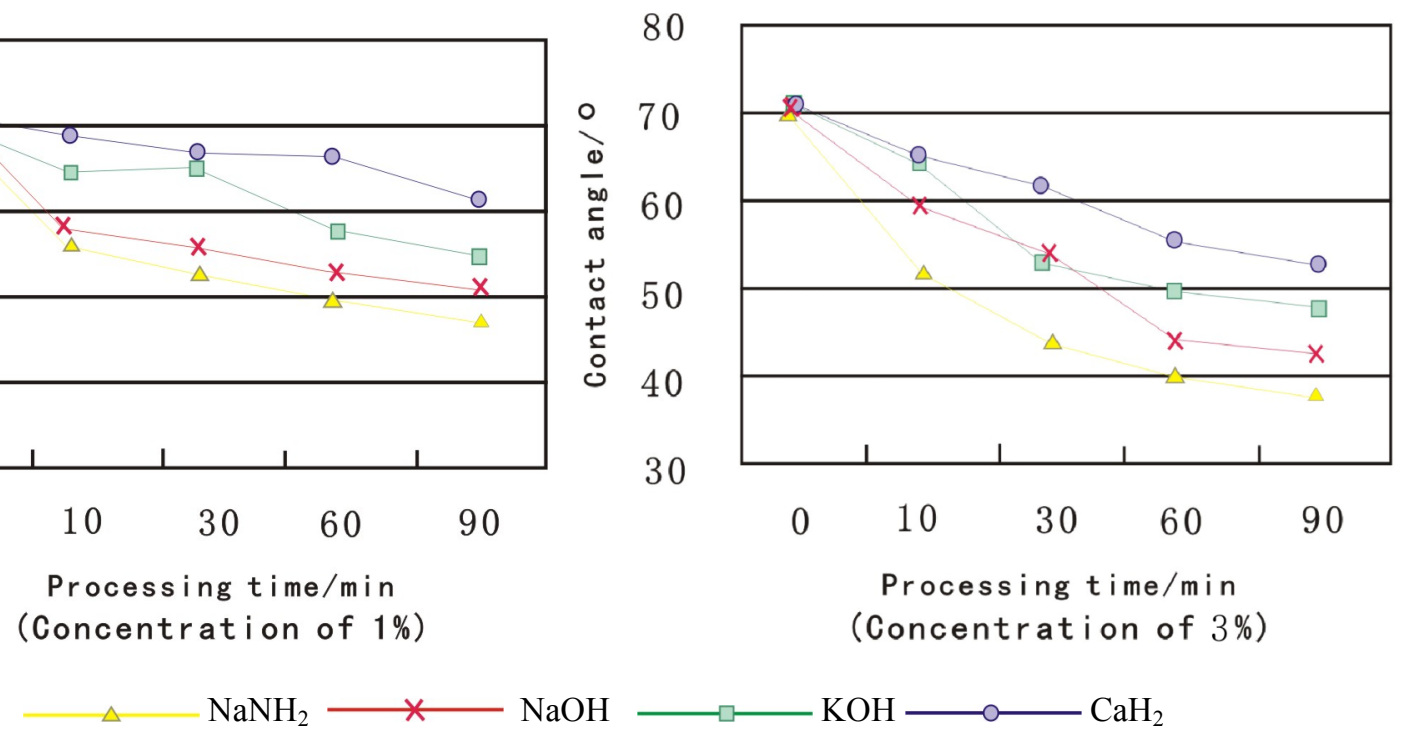

Fig. (9). Alkali treatment with different contact angle of rice straw on time change. 
(A)

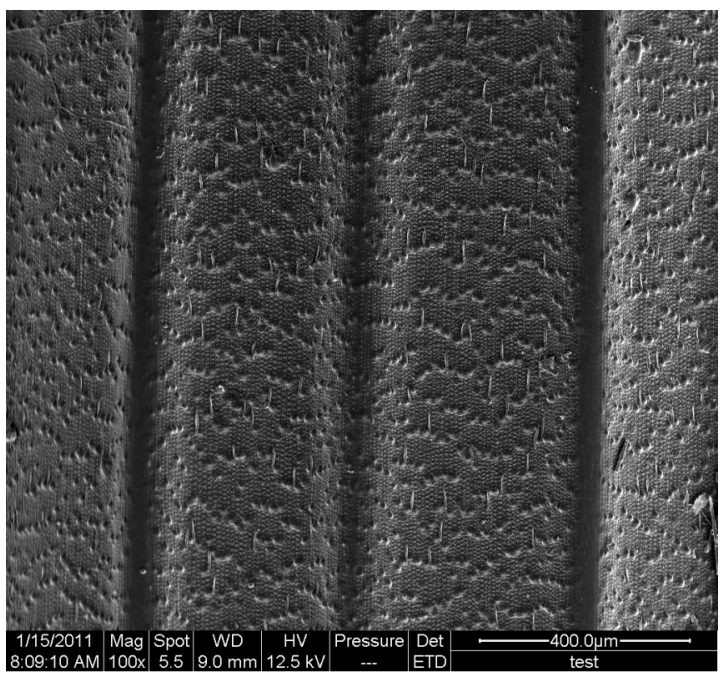

(C)

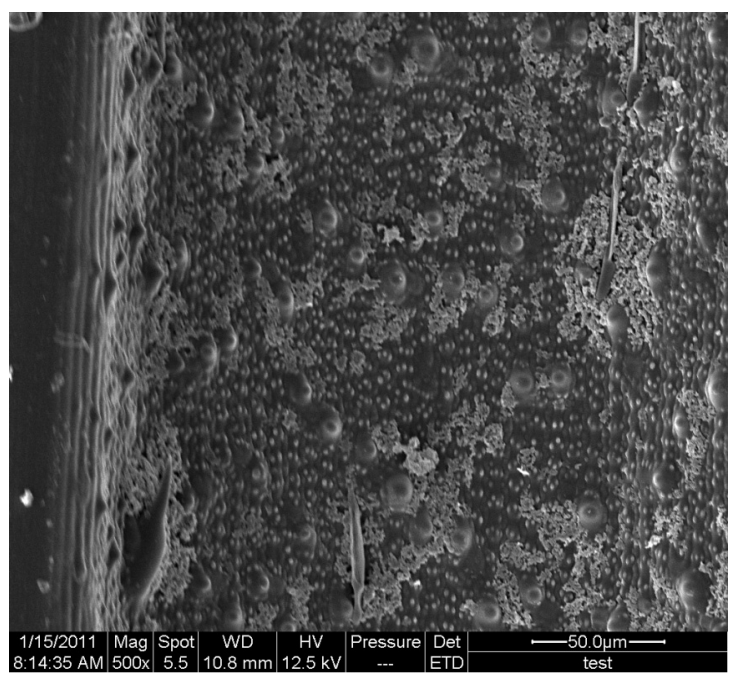

(B)

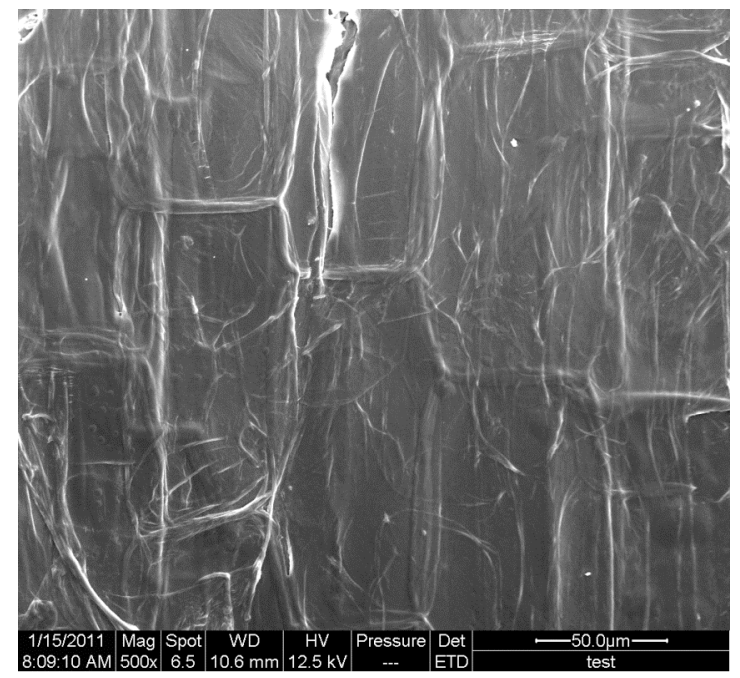

(D)

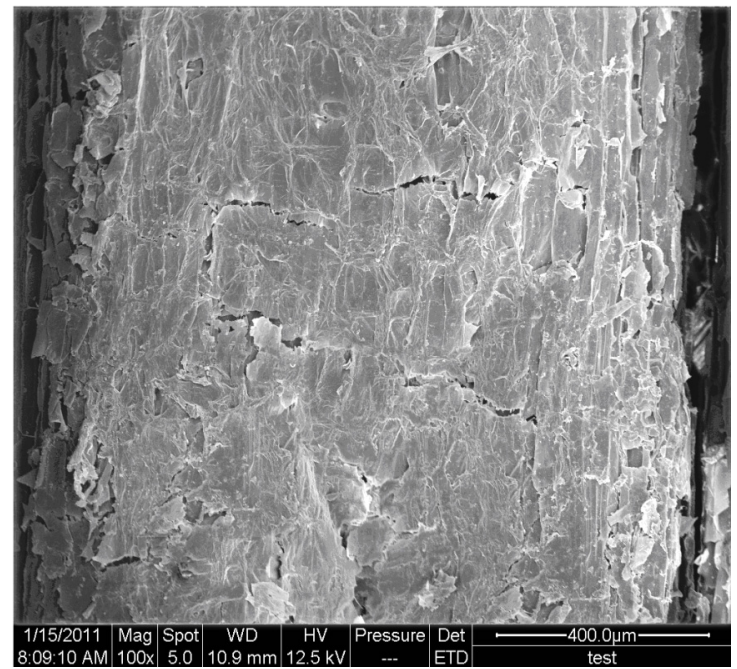

Fig. (10). Pretreatment of rice straw exterior and interior surface SEM images before and after. A. The exterior surface of rice straw before pretreatment. B. The interior surface of rice straw before pretreatment. C. The exterior surface of rice straw after $\mathrm{NaOH}$ treatment. D. The interior surface of rice straw after $\mathrm{NaOH}$ treatment.

different and diffusion permeability coefficient is different. This indicates that $\mathrm{NaOH}$ treatment of straw wax layer partially or completely destroyed the surface. Conducive to wettability and penetration of liquid and after $\mathrm{NaOH}$ treatment by drying the surface of a few free $\mathrm{NaOH}$ residual (pH 9.66) at the same time, this is beneficial to improve the tensile strength of particle board the plane. Later experiments prove that this management improves physical mechanical performance of rice straw particle board [34,35].

According to diffusion-permeability coefficient range analysis, we could know that the concentration of $\mathrm{NaOH}$ has the greatest impact and quality of materials used and the volume ratio of $\mathrm{NaOH}$ treatment time influence the same. Optimal solution according to the choice of orthogonal principle, the optimal program is obtained: $\mathrm{NaOH}$ concentration used is $0.15 \%$; solvent ratio is $1: 3.5$ and reaction time is $12 \mathrm{~h}$.

\section{CONCLUSIONS}

Based on the experimental results:
1. Established wetting model is used to describe contact angle changes as a function of time. The constant $(K$ value) in the model is used to quantify the spreading and penetrating rate of the liquid/straw system. As time went on, the contact angle decreases until it reaches equilibrium (force balance, heat balance, and chemical equilibrium); the straw unit surface area of water absorption is more form the surface free energy.

2. Four alkali treatments of rice straw to spray, contact angle changed with the reduced processing time. $\mathrm{NaOH}$ treatment effect changed significantly over time, and proved that $\mathrm{NaOH}$ can effectively improve the surface wetting properties of rice straw; $\mathrm{KOH}$ treatment effect changed little over time; $\mathrm{NaNH}_{2}$ processing rice straw and the contact angle of the mass $1 \%, 10 \mathrm{~min}$ rate of change within the maximum gradient of contact angle decreased 20.64\%; Under the same condition, $\mathrm{CaH}_{2}$ processing rice straw 
Table 4. Diffusivity-Permeability Coefficient $K$

\begin{tabular}{|c|c|c|c|c|c|c|c|c|c|c|}
\hline & $\mathbf{0}$ & $\mathbf{1}$ & $\mathbf{2}$ & $\mathbf{3}$ & $\mathbf{4}$ & $\mathbf{5}$ & $\mathbf{6}$ & $\mathbf{7}$ & $\mathbf{8}$ & $\mathbf{9}$ \\
\hline \hline$K$ & 0.00061 & 0.00176 & 0.00090 & 0.00162 & 0.03661 & 0.00155 & 0.00118 & 0.00925 & 0.01393 & 0.00098 \\
\hline
\end{tabular}

Table 5. The Results Range Analysis Table

\begin{tabular}{|c|c|c|c|c|c|}
\hline Experiment No. & $\begin{array}{l}\mathbf{A} \\
\mathbf{1}\end{array}$ & $\begin{array}{l}\text { B } \\
2\end{array}$ & $\begin{array}{l}\text { C } \\
3\end{array}$ & 4 & Diffusivity-Permeability Coefficient $K$ \\
\hline 1 & $1(0.3)$ & $1(1: 4.5)$ & $1(8)$ & 1 & 0.00176 \\
\hline 2 & $1(0.3)$ & $2(1: 2.5)$ & $2(12)$ & 2 & 0.000899667 \\
\hline 3 & $1(0.3)$ & $3(1: 3.5)$ & $3(24)$ & 3 & 0.00162 \\
\hline 4 & $2(1.5)$ & $1(1: 4.5)$ & $2(12)$ & 3 & 0.03661 \\
\hline 5 & $2(1.5)$ & $2(1: 2.5)$ & $3(24)$ & 1 & 0.00155 \\
\hline 6 & $2(1.5)$ & $3(1: 3.5)$ & $1(8)$ & 2 & 0.00118 \\
\hline 7 & $3(0.6)$ & $1(1: 4.5)$ & $3(24)$ & 2 & 0.00925 \\
\hline 8 & $3(0.6)$ & $2(1: 2.5)$ & $1(8)$ & 3 & 0.01393 \\
\hline 9 & $3(0.6)$ & $3(1: 3.5)$ & $2(12)$ & 1 & 0.00097795 \\
\hline K1 & 0.004279667 & 0.04762 & 0.01687 & $\mathrm{~K}=$ & 0.06777762 \\
\hline $\mathrm{K} 2$ & 0.03934 & 0.016379667 & 0.03848762 & $\mathrm{~W}=$ & 0.00622499 \\
\hline K3 & 0.02415795 & 0.003777953 & 0.01242 & & \\
\hline $\mathrm{k} 1$ & 0.00142655 & 0.01587333 & 0.00562333 & & \\
\hline k2 & 0.01311333 & 0.005459889 & 0.01282921 & & \\
\hline $\mathrm{k} 3$ & 0.008052651 & 0.0012593176667 & 0.00414 & & \\
\hline $\mathrm{Ri}$ & 0.01168677766 & 0.01461401566 & 0.00868920666 & & \\
\hline
\end{tabular}

reduces the contact angle of the gradient is the smallest, value is $3.6 \%$. Due to $\mathrm{CaH}_{2}$ dissolved in water and $\mathrm{CO}_{2}$ produce $\mathrm{CaCO}_{3}$.

3. After using OM and SEM, we analyzed that the main chemical composition of the smooth dense wax things on outer surface of wheat straw is a fatty alcohol and the formation of higher fatty acids esters. When smooth wax things is removed, and esters soluble in alkali. This rice straw wetting, diffusion and penetration create favorable conditions. Pictures can be seen from the $\mathrm{NaOH}$ treatment, the uneven surface of rice straw, a phenomenon similar to the "etching", and then the surface wettability of rice straw can be improved by $\mathrm{NaOH}$ treatment.

4. Optimal solution according to the choice of orthogonal principle, the optimal program is obtained: $\mathrm{NaOH}$ concentration used is $0.6 \%$; solvent ratio is $1: 3.5$ and reaction time is $12 \mathrm{~h}$.

\section{ACKNOWLEDGEMENTS}

The authors gratefully would like to acknowledge the College of Material Science and Engineering of Northeast Forestry University for supporting this work. The authors also would like to thank the financial support by Fundamental Research Funds for the Central Universities (DL09BB03).

\section{REFERENCES}

[1] Tavisto M, Kuisma R, Pasila A, Hautala M. Wetting and wicking of fibre plant straw fractions. Ind Crop Prod 2003; 18: 25-35.

[2] Shi Q, Wang JZ. Effect of density and polymer content on the hygroscopic thickness swelling rate of compression molded wood fiber/polymer composites. Wood Fiber Sci 2006; 38: 520-6.

[3] Shi SQ, Gardner DJ. Dynamic adhesive wettability of wood. Wood Fiber Sci 2001; 33: 58-68.

[4] Pan MZ, Zhou DG, Deng J, Zhang SY. Preparation and properties of wheat straw fiber-polypropylene composites. I. Investigation of surface treatments on the wheat straw fiber. J Compos Mater 2010; 44: 1061-73.

[5] Zerilli FJ, Armstrong RW. A constitutive equation for the dynamic deformation behavior of polymers. J Mater Sci 2007; 42: 4562-74.

[6] Wang ZL, Wang Z, Yan HP. Study on wheat straw surface free energy and its polar and non polar part. Polym Mater Sci Eng 2007; 23: $207-10$.

[7] Claus F, Jens H, Martin L. Pilotscale production of fiberboards made by laccase oxidized wood fibers: Board properties and evidence for cross-linking of lignin. Enzym Microb Tech 2002; 31: 736-41.

[8] Han GP, Deng J, Zhang SY, Bicho P, Wu QL. Effect of steam explosion treatment on characteristics of wheat straw. Ind Crop Prod. 2010; 31: 28-33.

[9] Tukayi K, Nyanhongo GS, Guebitz GM. Stephanie Potential applications of laccase-mediated coupling and grafting reactions: A review. Enzym Microb Tech 2011; 48: 195-208.

[10] Gianni P, Lisbeth O. Effect of compounds released during pretreatment of wheat straw on microbial growth and enzymatic hydrolysis rates. Biotechnol Bioeng 2007; 96: 250-8. 
[11] Liu ZM, Wang FH, Wang XM. Spectroscopic analysis of the interface for wheat straw specimen glued with PMDI. Wood Fiber Sci 2007; 39: 109-19.

[12] Anwar UMK, Hiziroglu S, Hamdan H, Abd LM. Effect of outdoor exposure on some properties of resin-treated plybamboo. Ind Crop Prod 2011; 33: 140-5.

[13] Micael S, Gardner DJ, Walinder MEP. Dynamic wettability of different machined wood surfaces. J Adhesion 2001; 76: 185-200.

[14] Han GP, Umemura K, Wong ED, Zhang M, Shuichi K. Effects of silane coupling agent level and extraction treatment on the properties of UF-bonded reed and wheat straw particleboards. J Wood Sci 2001; 47: 18-23.

[15] Hoong YB, Paridah MT, Loh YF, Jalaluddin H, Chuah LA. A new source of natural adhesive: Acacia mangium bark extracts copolymerized with phenol-formaldehyde (PF) for bonding Mempisang (Annonaceae spp.) veneers. Int J Adhes Adhes 2011; 31: 164-7.

[16] Hoong YB, Paridah MT, Luqman CA, Koh MP, Loh YF. Fortification of sulfited tannin from the bark of Acacia mangium with phenol-formaldehyde for use as plywood adhesive. Ind Crop Prod 2009; 30: 416-21.

[17] Hoong YB, Paridah MT, Loh YF, Koh MP, Luqman CA, Zaidon A. Acacia mangium tannin as formaldehyde scavenger for low molecular weight phenol-formaldehyde resin in bonding tropical plywood. J Adhes Sci Technol 2010; 24: 1653-64.

[18] Mohammed H, Mathieu P, Andre Z. Investigation of wood wettability changes during heat treatment on the basis of chemical analysis. Polym Degrad Stabil 2005; 89: 1-5.

[19] Shupe TE, Hse CY, Choong ET, Groom LH. Effect of wood grain and veneer side on loblolly pine veneer wettability. Forest Prod J 1998; 48: 95-7.

[20] Vazquez G, GonzálezÁlvarez J, Freire MS, Santos J, Uceira R, Antorrena G. Surface characterization of rotary-peeled eucalyptus veneers by confocal laser scanning microscopy and surface free energy and contact angle determination. WIT Trans Eng Sci 2009; 62: $241-50$.

[21] Maldas DC, Kamdem DP. Wettability of extracted southern pine. Forest Prod J 1999; 49: 91-3.

[22] Jan N, Kenneth S, Qing S, Rosenholm JB. Determination of surface energy and wettability of wood resins. Colloid Surf A 1998; 133: 261-8.
[23] Milojka G, Stefanie T. Significance of the acidity of wood to the surface free energy components of different wood species. Langmuir 2002; 18: 3209-12.

[24] Chen CM. Effect of extractive removal on adhesion and wettability of some tropical woods. Forest Prod J 1970; 20: 36-41.

[25] Hse CY. Wettability of southern pine veneer by phenol formaldehyde wood adhesives. Forest Prod J. 1972; 22: 51-6.

[26] Gindl M, Sinn G, Gindl W, Reiterer A, Tschegg S. A comparison of different methods to calculate the surface free energy of wood using contact angle measurements. Colloid Surf A 2001; 181: 27987.

[27] Wa linder MEP, Stro $\mathrm{m} \mathrm{G}$. Measurement of wood wettability by the Wilhelmy method. Part 2. Determination of apparent contact angles. Holzforschung 2001; 55: 33-41.

[28] Liu ZM, Wang FH, Wang XM. Surface structure and dynamic adhesive wettability of wheat straw. Wood Fiber Sci 2004; 36: 23949.

[29] Shen J. Wettability changes of wheat straw treated with chemicals and enzymes. J Forest Res 2001; 22: 107-10.

[30] Liu B, Wang FH, Jiao AY, Ye F, Sun JP. Study on the surface dynamic wettability of rice straw. 2nd International Conference on Mechanical and Electronics Engineering. IEEE Computer Society: Kyoto, Japan 2010.

[31] Zhu XD, Wang FH, Liu Y. Study on manufacturing process of ricestraw based board with fire-retardant. J Build Mater 2010; 13: 1304.

[32] Basta AH, Fierro V, El-Saied H, Celzard A. 2-Steps KOH activation of rice straw: An efficient method for preparing highperformance activated carbons. Bioresource Technol 2009; 100: 3941-7.

[33] Savastano HJ, Warden PG, Coutts RSP. Potential of alternative fiber cements as building materials for developing areas. Cement Concrete Comp 2003; 25: 585-92.

[34] Liu B, Wang FH, Jiao AY, Sun JP, Zhen MY. Dynamic wettability of rice straw. Adv Mater Res 2010; 154-5: 1783-7.

[35] Salim H, Songklod J, Vallayuth F, Piyawade B, Worakit S, Touchpong D. Properties of bamboo-rice straw-eucalyptus composite panels. Forest Prod J 2005; 55: 221-5.

(C) Liu et al.; Licensee Bentham Open.

This is an open access article licensed under the terms of the Creative Commons Attribution Non-Commercial License (http://creativecommons.org/licenses/by$\mathrm{nc} / 3.0 /$ ) which permits unrestricted, non-commercial use, distribution and reproduction in any medium, provided the work is properly cited. 